\title{
Effects of Mutual Interaction between Constituent Elements on Phase Formation of High Entropy Alloys
}

\author{
Anil Kumar ${ }^{*}$ and Manoj Chopkar
}

Department of Metallurgical Engineering, National Institute of Technology, Raipur, India

\author{
${ }^{*}$ Corresponding author: Anil Kumar, Department of Metallurgical Engineering, National Institute of \\ Technology, Raipur, India, E-mail: akumar.phd2013.met@nitrr.ac.in
}

Citation: Anil Kumar, Manoj Chopkar (2017) Effects of Mutual Interaction between Constituent Elements on Phase Formation of High Entropy Alloys. J Mater Sci Nanotechnol 5(2): 201

Received Date: December 01, 2016 Accepted Date: July 26, 2017 Published Date: August 02, 2017

\begin{abstract}
High entropy alloys (HEAs) are alloys that contains multiple elements, often five or more principal elements in equiatomic or near equiatomic ratio with or without minor elements. As felt from the name, high mixing entropy is the sole parameter to decide the solid solution alloy formation in HEAs but, the mutual interaction between elements are key parameters to predict the phase formation in HEAs as proposed by some researchers. In this review the guideline for alloy design in HEAs for the formation of solid solution phases are proposed on basis of atomic size difference $(\delta)$, mixing entropy $(\Delta \mathrm{Smix})$, mixing enthalpy $(\Delta \mathrm{Hmix})$, valence electron concentration (VEC) and electronegativity difference $(\Delta \chi)$. Effect of one more parameter $\Omega$ is also discussed. $\Omega$ is a parameter of the entropy of mixing timing and the average melting temperature of the elements over the enthalpy of mixing. Solid solution phase forms only when the requirement of these parameters are all met. These parametric constraints will lend a valuable motivation for future developments in HEAs.
\end{abstract}

Keywords: High entropy alloys; Atomic size difference solid solution; Crystal structure; Solid solution

\section{Introduction}

After the development of bulk metallic glasses (BMGs), high entropy alloys (HEAs) emerged as an advanced metallic material. The concept of HEAs was introduced by Achard in the late of eighteen century, then in the mid of 1900s Yeh and his colleagues explored the world of multicomponent alloys [1,2]. HEAs are often in single solid solution form has been attracting extensive research of materials community for their excellent properties like wear resistance, high hardness, softening resistance at higher temperature, corrosion and oxidation resistance. The alloy design concept in HEAs is beyond the realm of traditional powder metallurgy concept. The phase formation in HEAs are typically solid solution FCC and/or BCC structured which is far from intermetallic compounds formation in conventional physical metallurgy process. Thus, HEAs be given notable attention in last one decade. State of the art gives a significant idea that most studies in HEAs are focused on phase identification, microstructures, mechanical and physical properties [3-8]. Although to a small extent the attention was paid to the effect of atomic size, valence electrons and electronegativity of constituent elements on HEAs, they are as the truth also quite encouraging $[9,10]$.

Notably, when the amounts of $\mathrm{Al}, \mathrm{Cu}, \mathrm{Mo}, \mathrm{Nb}, \mathrm{Si}$, Ti, and $\mathrm{V}$ increases beyond a certain limit then, phase change in $\mathrm{HEAs}$ occurs for the combination of certain elements. In AlCoCrFeNiTi ${ }_{x}$ the addition of Ti changes BCC phase to BCC1 (AlNi rich) and BCC2 (Fe-Cr rich) due to lattice expansion shifting of phase towards lower $2 \theta$ value [11]. Similarly, in $\mathrm{Al}$ CoCrCuFeNi $\mathrm{HEAs}$ without $\mathrm{Al}$ $(\mathrm{x}=0)$ the FCC structure obtained but, by adding $\mathrm{Al}$ in this combination tunes the FCC structure to FCC+BCC structure $(\mathrm{x}=1-1.3)$. Further addition of $\mathrm{Al}(\mathrm{x}=2.3-3)$ converts the FCC+BCC crystal structure to BCC structure [12,13]. He JY, et al. synthesized a series of (FeCoNiCrMn) 100- $\mathrm{Al}_{\mathrm{x}}(\mathrm{x}=0-20$ at.\%) to investigate the effect of $\mathrm{Al}$ addition on the tensile properties [14]. They concluded that, tensile strength increases and ductility decreases with the $\mathrm{Al}$ addition and hence brittleness of HEAs increases due to formation of BCC phase. The aim of this review is hence to get idea of physical parameters that strongly dominance the stability of FCC and BCC phases in HEAs.

\section{Analysis}

The effect of vanadium $(\mathrm{V})$ addition on the microstructure and mechanical properties of as cast $\mathrm{AlCoCrFeNiV}_{\mathrm{x}}, \mathrm{Al}_{0.5} \mathrm{CoCrFeCuFeNiV}_{\mathrm{x}}$ and $\mathrm{CoCrFeMnNiV}$. HEAs have been studies and remarked that vanadium greatly increases the hardness of the material and decreases the ductility due to formation of BCC phase with increase in V percentage $[15,16,17]$. The phase analysis report for 
$\mathrm{CoCrFeMnNiV}$ clearly indicates that without $\mathrm{Al}$ and $\mathrm{Cu}$ the phases are single solution FCC phases. In $\mathrm{AlCoCrFeNiV}_{\mathrm{x}}$ the phases obtained are totally BCC, whereas $\mathrm{Al}_{0.5} \mathrm{CoCrFeCuFeNiV}_{\mathrm{x}}$ shows both FCC and BCC phases $(\mathrm{x}=0.2-1)$. The conversion of FCC phase to $\mathrm{BCC}$ phase in $\mathrm{AlCoCrFeNiV}_{\mathrm{x}}$ is due to large atomic radius of $\mathrm{Al}$ compared to other compositional elements. Similarly, FCC+BCC phase obtained in $\mathrm{Al}_{0.5} \mathrm{CoCrFeCuFeNiV}_{\mathrm{x}}$ is due to $\mathrm{Al}$ is a $\mathrm{BCC}$ stabilizer and large positive enthalpy of $\mathrm{Cu}$ than other elements $[9,18]$. In $\mathrm{CoCrFeNiNb}_{\mathrm{x}}$ alloys, the FCC phase formed for the range of $\mathrm{x}=0.103-0.412$ whereas for $\mathrm{AlCoCrFeNb} \mathrm{Ni}_{\mathrm{x}} \mathrm{alloys}$ the phases obtained are BCC for $\mathrm{x}=0.1-0.75$ due to large atomic radius of $\mathrm{Nb}[19,20]$. Here also Al acts as a $\mathrm{BCC}$ stabilizer. The phase analysis of $\mathrm{Al}_{0.5} \mathrm{CoCrCuFeNiSi}_{\mathrm{x}}$ was done by Xiaotao Liu, et al., and they reported that for $\mathrm{x}=0.4$ the peaks of $\mathrm{BCC}$ phase appears corresponding to Si content and the intensity goes on increasing by increasing the Si content. Hence by Si addition the single solid solution of FCC phase transforms into FCC+BCC phase due to positive enthalpy of Cu. This results into segregation of $\mathrm{Cu}[21]$.

Zhu, et al. did intense work on AlCoCrCuFeNiMo and AlCoCrFeNiMo to investigate the effect of Mo as well as of Cu. Upto $\mathrm{x}=0-0.2$, the material exhibits combined BCC and FCC structure in earlier one after that only BCC phase formation occurs ( $\mathrm{x}=0.2-$ 1 ), whereas in latter composition only BCC phase was seen for $\mathrm{x}=0-0.1$ and further addition of Mo ( $\mathrm{x}=0.1-0.5)$ resulted into the formation of an unidentified a phase [22,23]. In HEAs, transition materials (TM) are the most studied elements and they have spin d-electrons. Therefore, it is also important to review the characteristic of d-electrons for structural stability in HEAs. Valence electron concentration and electronegativity are the two parameters that depends on the d-electrons. VEC is basically defined as the total electrons together with the d-electrons accommodated within the valence band [9,24]. Electronegativity is the property of an atom to attract electrons. One more very important factor as stated by hume-rothery in alloy design is atomic mismatch, also called atomic size difference. Atomic mismatch is also a critical issue within the new category of HEAs by taking into account the lattice distortion [25]. In present study we are considering these parameters to predict the stability of solid solution phases.

\section{Result and Discussion}

$\Delta \mathrm{H}_{\text {Mix }}, \Delta \mathrm{S}_{\text {Mix }}$, VEC, $\delta, \Delta \chi$, and $\Omega$ for a series of multicomponent alloys which are in equiatomic or near to equiatomic were statistically analysed and listed in Table 1 . The calculations of different parameters were done by Meidema's approach. All the listed alloys were prepared by casting technique and phase analysis was carried out in as cast condition. Table 1 shows the mixing enthalpy calculated by Miedema's approach.

\begin{tabular}{|c|c|c|c|c|c|c|c|c|c|c|c|}
\hline Element & $\mathbf{A l}$ & $\mathbf{S i}$ & $\mathbf{T i}$ & $\mathbf{V}$ & $\mathbf{C r}$ & $\mathbf{F e}$ & $\mathbf{C o}$ & $\mathbf{N i}$ & $\mathbf{C u}$ & $\mathbf{N b}$ & $\mathbf{M o}$ \\
\hline $\mathbf{A l}$ & & -19 & -30 & -16 & -10 & -11 & -19 & -22 & -1 & -18 & -5 \\
\hline $\mathbf{S i}$ & & & -66 & -48 & -37 & -35 & -38 & -40 & -19 & -56 & -35 \\
\hline $\mathbf{T i}$ & & & & -2 & -7 & -17 & -28 & -35 & -9 & 2 & -4 \\
\hline $\mathbf{V}$ & & & & & -2 & -7 & -14 & -18 & 5 & -1 & 0 \\
\hline $\mathbf{C r}$ & & & & & & -1 & -4 & -7 & 12 & -7 & 0 \\
\hline $\mathbf{F e}$ & & & & & & & -1 & -2 & 13 & -16 & -2 \\
\hline $\mathbf{C o}$ & & & & & & & & 0 & 6 & -25 & -5 \\
\hline $\mathbf{N i}$ & & & & & & & & & 4 & -30 & -7 \\
\hline $\mathbf{C u}$ & & & & & & & & & & 3 & 19 \\
\hline $\mathbf{N b}$ & & & & & & & & & & & -6 \\
\hline
\end{tabular}

Table 1: Mixing enthalpy (kj/mol) calculated by miedema’s approach [30]

According to the Hume-Rothery (H-R) rule, the atomic size difference is a potent parameter in controlling or determining the solubility of alloys. H-R rule for binary alloys, the atomic size difference is defined by $\left|r_{A}-r_{B}\right| / r_{B}$ where $r_{A}$ and $r_{B}$ are atomic radii of solute and solvent respectively. For simplicity, Zhang, et al. studied the collective behavior of constituent elements and gives the relation for atomic mismatch $(\delta)$, mixing enthalpy $\left(\Delta \mathrm{H}_{\mathrm{Mix}}\right)$, and mixing entropy $\left(\Delta \mathrm{S}_{\mathrm{Mix}}\right)$ on the solid solution phases of multicomponent alloy, which are:

$$
\delta=100 \sqrt{\sum_{i=1}^{n} C_{i}\left(1-\frac{r_{i}}{\bar{r}}\right)^{2}}
$$

Where $\bar{r}=\sum_{i=1}^{n} C_{i} r_{i}, \mathrm{n}$ is the number of alloying elements, $C_{i}$ and $r_{i}$ are the atomic percentage and atomic radius of the $i^{\text {th }}$ element respectively.

$$
\Delta H_{\text {mix }}=\sum_{i=1, i \neq j}^{n} \Omega_{i j} C_{i} C_{j}
$$


Where $\Omega_{i j}=4 \Delta_{m i x}^{A B}, \Delta_{m i x}^{A B}$ is the mixing enthalpy of binary liquid AB alloys and

$$
\Delta S_{m i x}=-R \sum_{i=1}^{n} C_{i} \ln C_{i}
$$

Where $\mathrm{R}$ is the gas constant $(8.314 \mathrm{~J} / \mathrm{mol}$. K) $[26,27]$.

Fang, et al. studied the relationship between the phase stability and electronegative difference in a multicomponent alloy system, which is given as

$$
\Delta \chi=\sqrt{\sum_{i=1}^{n} C_{i}\left(\chi_{i}-\bar{\chi}\right)^{2}}
$$

Where $\bar{\chi}=\sum_{i=1}^{n} C_{i} \chi_{i}, \chi_{i}$ is the Pauling Electronegativity for the $i^{\text {th }}$ element [28].

Gue and Thaddeus introduced the effect of valence electron concentration (VEC), which is the number of total electrons accommodated in valence band, given by

$$
V E C=\sum_{i=1}^{n} C_{i}(V E C)_{i}
$$

Where $(V E C)_{i}$ is the VEC for the $i^{\text {th }}$ element $[24,29]$.

In addition of these three critical parameters, another one more parameter, $\Omega$ is used to predict the phase formation behavior of HEAs, given as

$$
\Omega=\frac{T_{m} \Delta S_{m i x}}{\left|\Delta H_{m i x}\right|}
$$

Where $T_{m}$ is the melting temperature of n-elements alloy and calculated as $T_{m}=\sum_{i=1}^{n} C_{i}\left(T_{m}\right)_{i}$ here, $\left(T_{m}\right)_{i}$ is the melting point temperature of the $i^{\text {th }}$ element [21].

However, these empirical relationship criterion works for some combinations of the constituent elements to predict the stability of FCC and BCC solid solutions. Hence, the objective of this paper is to focus on the investigation of those physical parameters that would strongly predicts the stability of FCC and BCC phases in HEAs.

Tong, et al. discussed the effect of $\mathrm{Al}$ addition on microstructure and mechanical properties of $\mathrm{Al}_{\mathrm{x}} \mathrm{CoCrCuFeNi}$ multi-component alloy. They observed that when $\mathrm{x}<0.5$, the alloys showed a simple FCC structure. As $\mathrm{x}=0.8$, mixed FCC $+\mathrm{BCC}$ phases were observed. When $\mathrm{Al}$ contents $\mathrm{x}>1.0-2.8$ a single BCC structure was obtained due to spinodal decomposition. Hence, the structural transmission from $\mathrm{FCC} \rightarrow \mathrm{FCC}+\mathrm{BCC} \rightarrow \mathrm{BCC}$ and also increased hardness value were obtained. This is explained by higher atomic size of $\mathrm{Al}$ as compared to others and solid solution hardening and strong binding forces of $\mathrm{Al}$ with other metallic atoms [12]. Chen, et al. reported that the hardness value increased with titanium content in $\mathrm{Al}_{0.5} \mathrm{CoCrCuFeNiTi}_{\mathrm{x}}$. Upto 0.6 of Ti content, there was not much increase in wear resistance but, it increases rapidly with increasing the Ti content from 0.6 to 1.0 and reached a maximum at $\mathrm{x}=1.0[9]$.

From Figure 1 we can easily say that for light transition metal ( $\mathrm{Cr}, \mathrm{Mn}, \mathrm{Fe}, \mathrm{Co}, \mathrm{Ni}, \mathrm{Cu}$,) based HEAs the FCC phase shows higher mixing enthalpy but as the large size elements like $\mathrm{Al}, \mathrm{Ti}, \mathrm{V}$, and $\mathrm{Nb}$ is added, then the enthalpy decreases. For most of the materials which are studied in this paper shows the range of mixing enthalpy $-9.7 \leq \Delta H_{\text {mix }} \leq 3.2$ for FCC phase as shown in Figure 1. The ranges of VEC for all combinations, for VEC $\geq 7.95$, single BCC phase is not stable and most of the FCC phases are obtained in the region. Whereas for $7.2 \leq \mathrm{VEC} \geq 7.95$ all three combinations have been seen i.e., FCC, BCC and FCC+BCC but stability of BCC phase is high for the VEC $\leq 7.2$. Atomic mismatch $(\delta)$ of FCC phase ranges from $1.03 \leq \delta \leq 3.7$ whereas for BCC phase the range is $5.33 \leq \delta \leq 7.01$ and for FCC and FCC+BCC phases obtained in the range $3.7 \leq \delta \leq 7.01$.

The relation between mixing enthalpy $\left(\Delta H_{\text {mix }}\right)$ and atomic mismatch $(\delta)$ is clearly seen that, the value of $\delta$ increases by increasing the amount of element in composition whereas for the same compositions enthalpy decreases. Electronegativity $(\Delta \chi)$ variation is shown in Figure 1, and this indicates that for the value of $\Delta \chi \geq 0.138$ FCC phase was not stable whereas for $\Delta \chi \leq 0.11$ FCC and FCC+BCC phases are stable. Figure 2 confirms the relation between $\Delta H_{\text {mix }}$ and $\Omega$ as in mathematical expression that $\Delta H_{\text {mix }}$ and $\Omega$ are inversely proportional. 


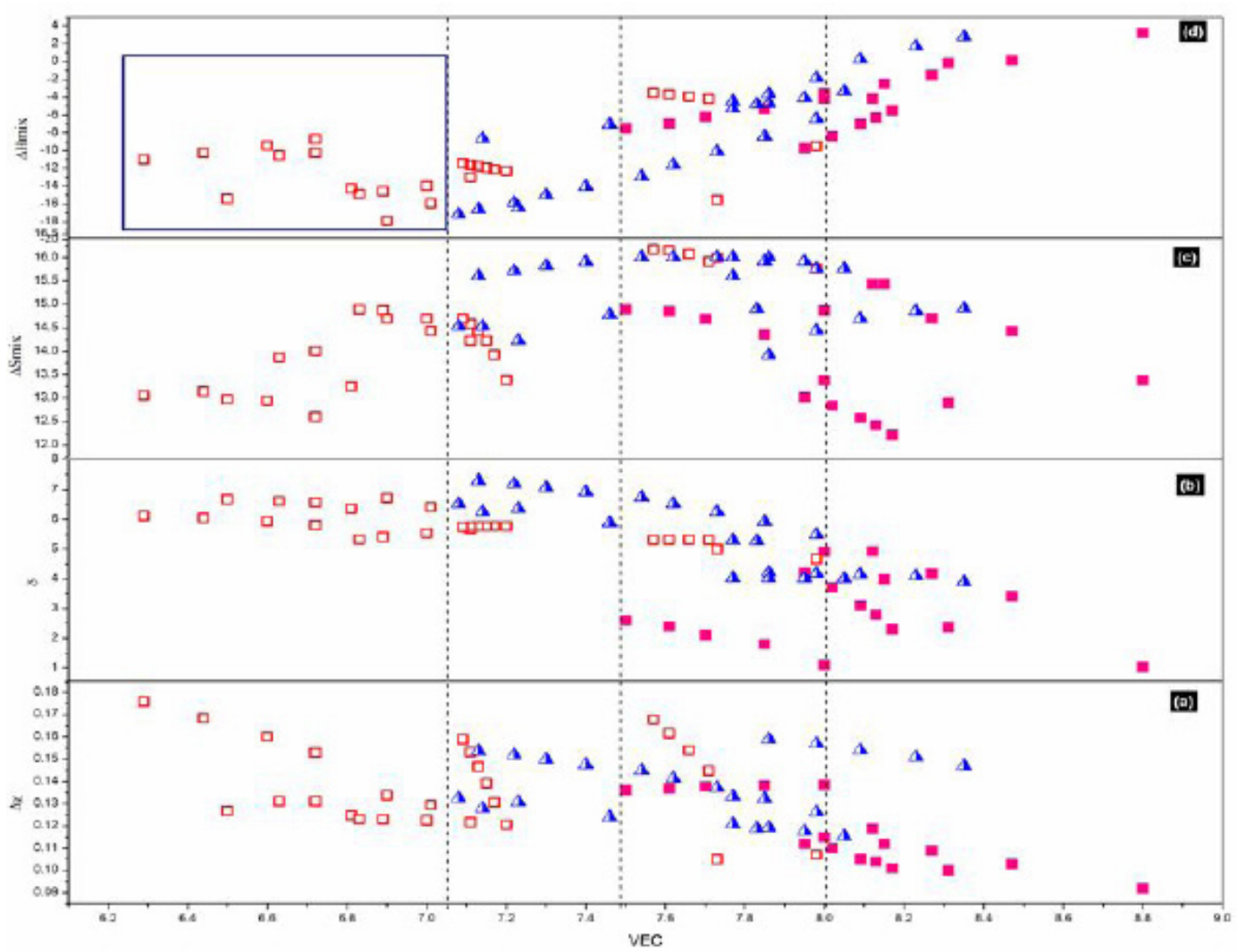

Figure 1: Variation of different parameters with Valence Electron Concentration (VEC). Note on the Legend: Fully Closed Symbols for Sole FCC, Fully Open Symbols for Sole BCC Phase; Right-Half Closed Symbols for Mixes FCC and BCC Phases

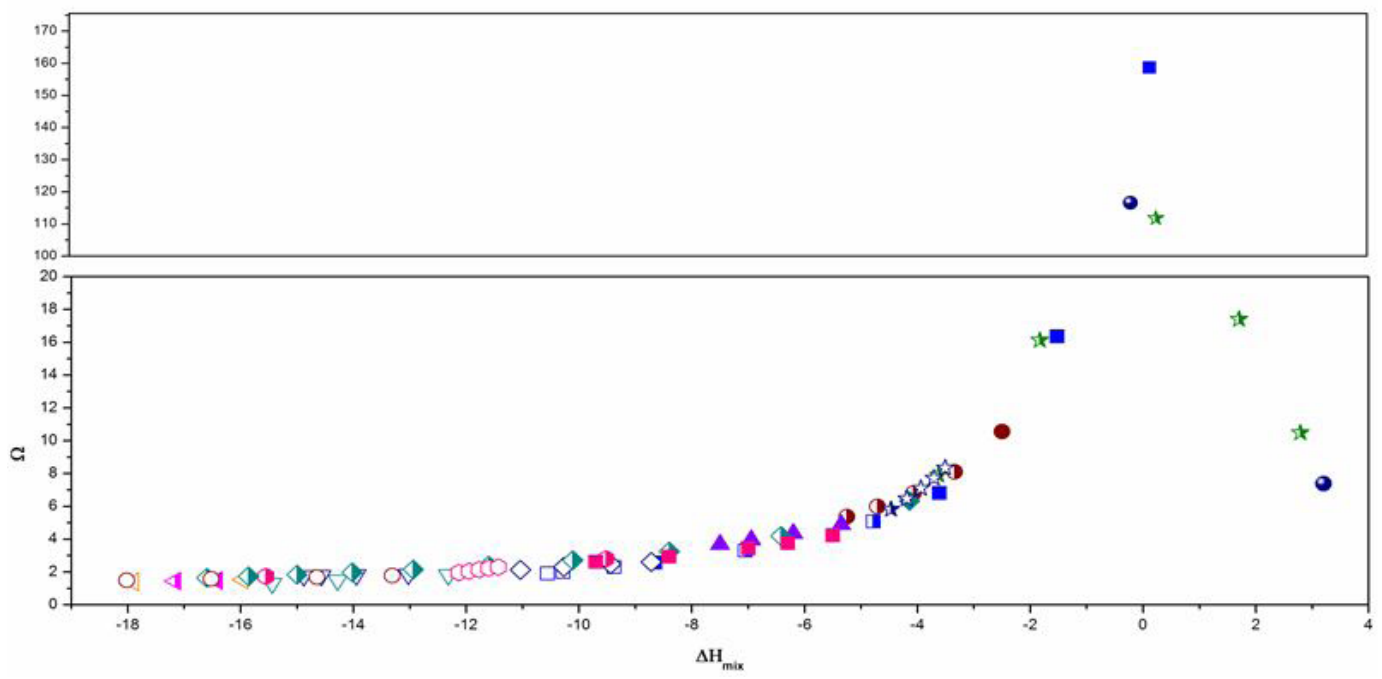

Figure 2: Variation of $\Omega$ with respect to mixing enthalpy $\left(\Delta H_{m i x}\right)$ for variety of high entropy alloys

The critical value $\Omega=1$ is proposed to form the solid solution. If $\Omega>1$, the solid solution formation will be more and if $\Omega \leq 1$ intermetallic compound formation and also segregation will exceed that of solid solution to form [13,31]. The analysis done in this work of $\Omega$ also satisfies the condition given above. However, the exactness of these criterion requires more experimental analysis to make sure. Figure 2 shows the variation of different parameters with respect to valence electron concentration. This clearly indicates that, the beyond the 7.25 value of VEC, mixing enthalpy goes on increase. But, changes in cases of mixing entropy, atomic size mismatch and electronegativity variation in values with VEC value does not follows any specific pattern.

\section{Conclusion}

Phase selection analysis for as cast high entropy alloys prepared by different researchers have been studied based on thermodynamic approach as well as geometric effect. Notably, the high mixing entropy is not only criteria to predict the BCC, BCC and FCC+BCC solid solution phases in equiatomic or non equiatomic multi component system. Some empirical conditions have been summarized here for the prediction of phases in HEAs. The mixing enthalpy, valence electron concentration, atomic size mismatch and 
electronegativity are of great importance to control the FCC and BCC phase formation. VEC $\geq 7.95$, FCC phases are stable whereas, stability of BCC phase is high for the VEC $\leq 7.2$. For $7.2 \leq \mathrm{VEC} \geq 7.95$ all three combinations have been seen i.e., FCC, BCC and FCC+BCC. Another important parameter is atomic size mismatch, here FCC phase is stable for $\delta \leq 3.7$ and instead BCC phases are obtained for $\delta \geq 5.33$. Effect of electronegativity is also discussed in this paper and observed that for $\Delta \chi \geq 0.138$ FCC phase was not stable whereas for $\Delta \chi \leq 11.5$ FCC and FCC+BCC phases are stable. One more parameter $\Omega$ is calculates for multi component HEAs and gives the idea that for stabilized solid solution phase formation, the $\Omega$ should be $\Omega \geq 1$.

\section{References}

1. Murty BS, Yeh JW, Ranganathan S (2014) A Brief History of Alloys and the Birth of High-Entropy Alloys. High Entropy Alloys 1-12.

2. Ranganathan S (2003) Alloyed pleasures: Multimetallic cocktails. Current Sci 85: 1404-6.

3. Chuang MH, Tsai MH, Wang WR, Lin SJ, Yeh JW (2011) Microstructure and wear behavior of $\mathrm{Al}_{x} \mathrm{Co}_{1.5} \mathrm{CrFeNi}_{1.5}$ Tiy high-entropy alloys. Acta Mater 59: 6308-17. 4. Cantor B (2014) Multicomponent and High Entropy Alloys. Entropy 16: 4749-68.

5. Chen MR, Lin SJ, Yeh JW, Chen SK, Huang YS, et al. (2006) Microstructure and Properties of $\mathrm{Al}_{0.5} \mathrm{CoCrCuFeNiTi}_{\mathrm{x}}$ ( $\left.\mathrm{x}=0-2.0\right)$ High-Entropy Alloys. Mater Trans 47: 1395-1401.

6. Senkov ON, Scott JM, Senkova SV, Miracle DB, Woodward CF (2011) Microstructure and room temperature properties of a high-entropy TaNbHfZrTi alloy. J. Alloys Compd 509: 6043-48.

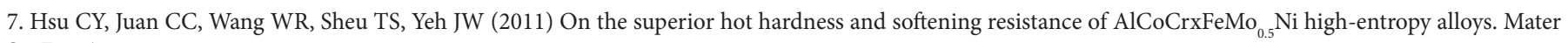
Sci Eng A 528: 3581-8.

8. Zhou YJ, Zhang Y, Wang YL, Chen GL (2007) Solid solution alloys of AlCoCrFeNiTi with excellent room-temperature mechanical properties. Appl Phys Lett 90: 181904 .

9. Guo S, Chun Ng, Jian Lu, Liu CT (2011) Effect of valence electron concentration on stability of fcc or bcc phase in high entropy alloys. J Appl Phys $109: 103505$. 10. Dong Y, Lu Y, Jiang L, Wang T, Li T (2014) Effects of electro-negativity on the stability of topologically close-packed phase in high entropy alloys. Intermetallics 52: 105-9.

11. Yu Y, Wang J, Li J, Kou H, Liu W (2015) Characterization of BCC phases in AlCoCrFeNiTi high entropy alloys. Mater Lett 138: 78-80.

12. Tong CJ, Chen YL, Yeh JW, Lin SJ, Chen SK, et al. (2005) Microstructure characterization of $\mathrm{Al}_{\mathrm{x}} \mathrm{CoCrCuFeNi}$ high-entropy alloy system with multiprincipal elements. Metall Mater Trans A 36: 881-93.

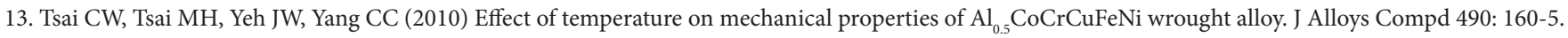

14. He JY, Liu WH, Wang H, Wu Y, Liu XJ, et al. (2014) Effects of Al addition on structural evolution and tensile properties of the FeCoNiCrMn high-entropy alloy system. Acta Mater 62: 105-13.

15. Dong Y, Zhou K, Lu Y, Gao X, Wang T, et al. (2014) Effect of vanadium addition on the microstructure and properties of AlCoCrFeNi high entropy alloy. Mater Des 57: 67-72.

16. Stepanov ND, Shaysultanov DG, Salishchev GA, Tikhonovsky MA, Oleynik EE, et al. (2015) Effect of V content on microstructure and mechanical properties of the $\mathrm{CoCrFeMnNiV}$, high entropy alloys. J Alloys Compd 628: 170-85.

17. Chen MR, Lin SJ, Yeh JW, Chuang MH, Chen SK, et al. (2006) Effect of vanadium addition on the microstructure, hardness, and wear resistance of $\mathrm{Al}_{0.5} \mathrm{CoCrCuFeNi} \mathrm{high-entropy} \mathrm{alloy.} \mathrm{Metall} \mathrm{Mater} \mathrm{Trans} \mathrm{A} \mathrm{37:} \mathrm{1363-9.}$

18. Hsu YJ, Chiang WC, Wu JK (2005) Corrosion behavior of $\mathrm{FeCoNiCrCu}_{\mathrm{x}}$ high-entropy alloys in 3.5\% sodium chloride solution. Mater Chem Phys 92: $112-7$.

19. Ma SG, Zhang Y (2012) Effect of Nb addition on the microstructure and properties of AlCoCrFeNi high-entropy alloy. Mater Sci Eng A 532: $480-6$.

20. Cheng JB, Liang XB, Xu BS (2014) Effect of Nb addition on the structure and mechanical behaviors of CoCrCuFeNi high-entropy alloy coatings. Surf Coatings Tech 240: 184-90.

21. Liu X, Lei W, Ma L, Liu J, Liu J, et al. (2015) On the microstructures, phase assemblages and properties of $\mathrm{Al}_{0.5} \mathrm{CoCrCuFeNiSi}_{\mathrm{x}}$ high-entropy alloys. J Alloys Compd 630: 151-7.

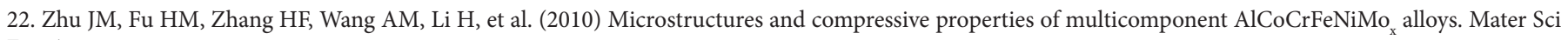
Eng A 527: 6975-9.

23. Zhu JM, Zhang HF, Fu HM, Wang AM, Li H, et al. (2010) Microstructures and compressive properties of multicomponent AlCoCrCuFeNiMo alloys. J Alloys Compd 497: 52-6.

24. Massalski TB (2010) Comments Concerning Some Features of Phase Diagrams and Phase Transformations. Mater Trans 51: 583-96.

25. Wang Z, Qiu W, Yang Y, Liu CT (2015) Atomic-size and lattice-distortion effects in newly developed high-entropy alloys with multiple principal elements. Intermetallics 64: 63-9.

26. Yang X, Zhang Y (2012) Prediction of high-entropy stabilized solid-solution in multi-component alloys. Mater Chem Phys 132: 233-8.

27. Zhang Y, Zuo TT, Tang Z, Gao MC, Dahmen KA, et al. (2014) Microstructures and properties of high-entropy alloys. Prog Mater Sci 61: 1-93.

28. Fang S, Xiao X, Xia L, Li W, Dong Y (2003) Relationship between the widths of supercooled liquid regions and bond parameters of Mg-based bulk metallic glasses. J Non Cryst Solids 321: 120-5.

29. Guo S, Liu CT (2011) Phase stability in high entropy alloys: Formation of solid-solution phase or amorphous phase. Prog Nat Sci Mater Int 21: 433-46.

30. Hsu CY, Sheu TS, Yeh JW, Chen SK (2010) Effect of iron content on wear behavior of AlCoCrFe $\mathrm{Mo}_{0.5} \mathrm{Ni}$ high-entropy alloys. Wear 268: 653-9.

31. Li C, Li JC, Zhao M, Jiang Q (2009) Effect of alloying elements on microstructure and properties of multiprincipal elements high-entropy alloys. J Alloys Compd 475: 752-7.

32. Wu PH, Liu N, Yang W, Zhu ZX, Lu YP, et al. (2015) Microstructure and solidification behavior of multicomponent $\mathrm{CoCrCu}_{\mathrm{x}}$ FeMoNi high-entropy alloys. Mater Sci Eng A 642: 142-9.

33. Wang FJ, Zhang Y (2008) Effect of Co addition on crystal structure and mechanical properties of $\mathrm{Ti}_{0.5}$ CrFeNiAlCo high entropy alloy. Mater Sci Eng A 496: 214-6. 
34. Liu WH, He JY, Huang HL, Wang H, Lu ZP, et al. (2015) Effects of Nb additions on the microstructure and mechanical property of CoCrFeNi high-entropy alloys. Intermetallics 60: 1-8.

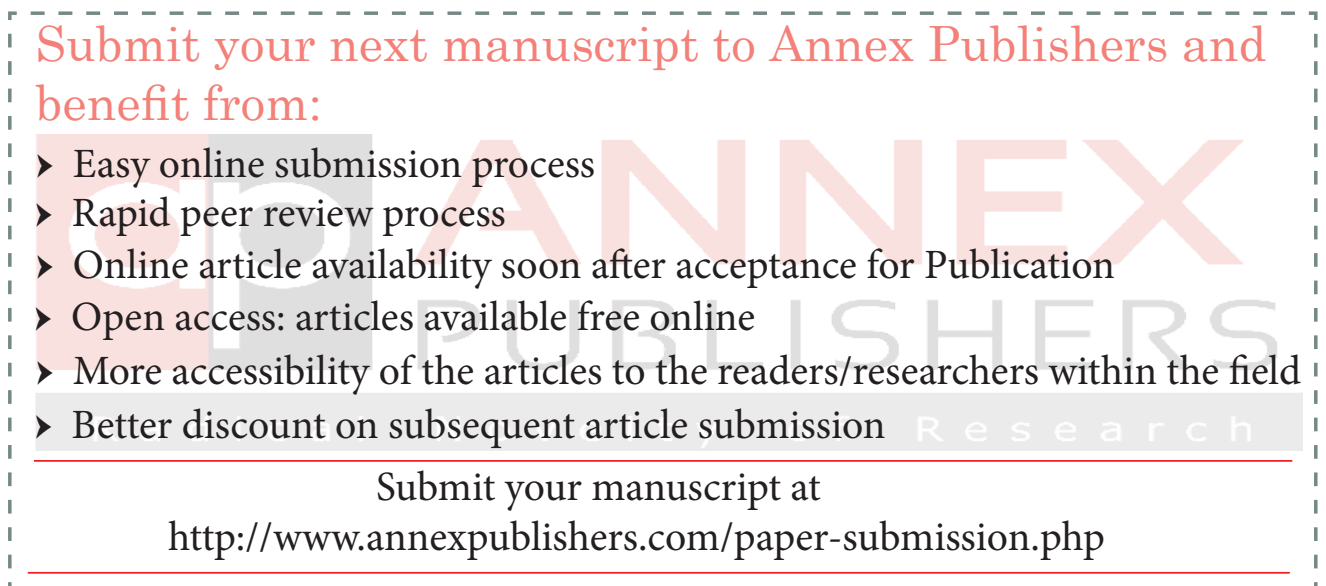

